\title{
Clinicopathologic study of large abdominal masses in gynaecological practice and their outcome
}

\author{
Pooja Mathur*, Anupama Dave, Poonam Gaur, Poonam Mathur
}

\begin{abstract}
Department of Obstetrics and Gynaecology, Mahatma Gandhi Memorial Medical College and Maharaja Yashwantrao Hospital, Indore, Madhya Pradesh, India
\end{abstract}

Received: 12 January 2016

Accepted: 29 January 2016

\author{
*Correspondence: \\ Dr. Pooja Mathur, \\ E-mail: poojamathur2604@gmail.com
}

Copyright: () the author(s), publisher and licensee Medip Academy. This is an open-access article distributed under the terms of the Creative Commons Attribution Non-Commercial License, which permits unrestricted non-commercial use, distribution, and reproduction in any medium, provided the original work is properly cited.

\begin{abstract}
Background: In female reproductive tract the differential diagnosis of pelvic mass is quite variable because abnormality may arise from gynaecological or non-gynaecological origin. The aim of the present study is to find out the causes why these patients come with large abdominal masses, to find out the risk factors and to do proper management.

Methods: This study is a retrospective study of all cases of large abdominal mass All the patient coming with palpable abdominal and pelvic adnexal mass in the gynaecologic OPD were included in the study. Study population included women of all ages and the relevant population of women with treatment for fibroids and ovarian mass. The data was analysed retrospectively and the results were computed accordingly.

Results: Incidence of large ovarian mass was found out to be $2.82 \%$ and of large fibroid was $2.31 \%$. Our study showed the peak incidence of ovarian tumors in age group more than 40 years. $90.5 \%$ of patients were illiterate and only 10 patients were literate. In the study only $8.57 \%$ patients had addiction to some drug and all were tobacco chewer. The incidence of benign tumor was $83.33 \%$ (commonest being ovarian tumours) and that of malignant tumors is $16.66 \%$.

Conclusions: Ultrasound is effective in detecting the abdominal mass, size and type of abdominal mass, so that early diagnosis can be done and treatment can be given as soon as possible. Apart from already established risk factors, obesity and uterine fibroid have an important association.
\end{abstract}

Keywords: Abdominal mass, Gynecological mass, Ovarian tumour

\section{INTRODUCTION}

Gynaecologists are often confronted with the dilemma of differentiating malignant tumours from benign in patients presenting with pelvic mass or presumptive diagnosis of liomyomata. ${ }^{1}$ In female reproductive tract the differential diagnosis of pelvic mass is quite variable because abnormality may arise from gynaecological or nongynaecological origin. ${ }^{1,2}$ Gynaecological masses are either uterine or adnexal. Adnexal region is composed of ovary, fallopian tube, broad ligament, and associated blood and nerve supply. ${ }^{3,4}$ While non-gynaecological sources of pelvic masses are those arising from bladder, ureter, rectum, colon, blood vessels and nerves in the pelvis. 5

Ovarian pathology is responsible for $70 \%$ of pelvic masses found at exploratory surgery on patients with preoperative diagnosis of pelvic mass, not attributable to leiomyomata. ${ }^{6}$ Among the abdominal masses, uterine fibroids are the most common pelvic tumours of women. Being a major cause of abnormal uterine bleeding they are the most commonly cited reason for hysterectomy. ${ }^{7-9}$

The standard evaluation of adnexal masses includes history, physical examination, ultrasound evaluation and 
tumours markers and final confirmation after biopsy. Other imaging techniques used are computerised tomography and magnetic resonance imaging. Final diagnosis is reached at laparoscopy or laparotomy. At the time of operation, appropriate incision would allow careful staging. The preoperative diagnosis of ovarian cancer might reduce the need for repeat laparotomies and could lead to timely referral to gynaecological oncologists. $^{10-15}$

The aim of the present study is to find out the causes why these patients come with large abdominal masses, to find out the risk factors and to do proper management.

\section{Aims and objectives}

- $\quad$ To study the incidence of palpable abdominal mass in gynaecological patients of a tertiary care hospital.

- To study the various risk factors leading to palpable abdominal mass and its associated morbidity.

- To study the overall clinical profile of patients diagnosed with palpable abdominal mass.

- To study the inpatient surgical treatment patterns for patients with palpable abdominal mass.

\section{METHODS}

This study is a retrospective study of all cases of large abdominal mass presenting during September 2010 to September 2012. Study population includes women of all ages and the relevant population of women with treatment for fibroids and ovarian mass.

Patients admitted in gynecological ward in department of obstetrics and gynecology in a tertiary care hospital from July 2010 to September 2012 diagnosed with uterine fibroid and ovarian mass were selected for the study.

The Criteria for diagnosis either by clinical features, USG findings and hysterectomy or confirmed by histopathological examination.

All the patient coming with palpable abdominal and pelvic adnexal mass in the gynecologic OPD were included in the study irrespective of age, parity, symptomatology, marital status etc.
A detailed history of each case was recorded with reference of age, religion, parity, socioeconomic status, symptomatology, marital status, menstrual history, obstetric history, family history, and history of contraceptive methods, method adopted and history of present and past medical and surgical illness.

A thorough clinical examination including per abdominal, per speculum, per vaginal and per rectal examination was noted for each case. All the relevant routine and special investigations including MRI/CT findings CA-125 levels were noted down.

After surgery, the intraoperative findings about the origin of mass were noted from intra-op notes. Details to size, weight, numbers of tumors, type of tumor, examination of gross nature of the mass and secondary changes in tumors and histopathological report were studied. All patients suspected to have malignancy referred to cancer hospital for further management were followed up.

\section{RESULTS}

Incidence of large ovarian mass in present study conducted at a tertiary care hospital was found out to be $2.82 \%$ and incidence of large fibroid was $2.31 \%$ \& others were $0.15 \%$. The maximum number of patients was in the age group of more than 40 years. The range of age was 15-70 years. Our study showed the peak incidence of ovarian tumours in age group more than 40 year and in between 21-25 years, also $10.91 \%$ case of malignancy were seen in patients over 40 years (Table 1 ).

$90.5 \%$ of patients were illiterate and only 10 patients were literate. In the study only $8.57 \%$ patients had addiction to some drug and all were tobacco chewer.

In the present study the incidence of benign tumour is $83.33 \%$ (commonest being ovarian tumours) and that of malignant tumour is $16.66 \%$. The commonest type of ovarian tumour according to WHO classification was surface epithelial tumours $(50.5 \%)$. Among the surface epithelial tumours, serous cyst adenoma was the comments one $(24.44 \%)$ followed by mucinous cyst adenoma $(6.66 \%)$. Second most common tumour seen in our study was germ cell tumour (22.2\%). Mature cystic teratoma $(20 \%)$ was the commonest type of germ cell tumour.

Table 1: Distribution of palpable abdominal mass in different age group.

\begin{tabular}{|c|c|c|c|c|c|c|c|c|}
\hline & & $16-20 \mathrm{yrs}$ & 21-25 yrs & 26-30 yrs & 31-35 yrs & $36-40$ yrs & $>40$ yrs & Total \\
\hline \multirow{2}{*}{ Ovarian } & Benign & 3 & 8 & 1 & 3 & 7 & 15 & \multirow{2}{*}{55} \\
\hline & Malignant & 0 & 3 & 3 & 4 & 0 & 6 & \\
\hline Fibroid & - & 1 & 10 & 12 & 10 & 7 & 5 & 46 \\
\hline Others & - & - & - & 3 & - & - & - & 3 \\
\hline Total & & & & & & & & 104 \\
\hline
\end{tabular}


Out of total cases of ovarian cyst (both benign and malignant), bilateral involvement was found in $21.81 \%$ and right side involvement was found in $52.72 \%$. Maximum number of tumours is of size upto $10 \mathrm{~cm}$ $(52.88 \%)$ and more than $20 \mathrm{~cm}$ is found in $3.84 \%$ cases. Also, 6 cases $(5.76 \%)$ were associated with pregnancy. Out of 6 one case was associated with intramural fibroid and 5 cases with ovarian mass.

In the present study, as in table 3, pelvic pain was present in $75 \%$ cases. Abdominal pain with distension was present $26.92 \%$. Abdominal lump was present $16.34 \%$. Pressure symptoms like constipation was present in $18 \%$ and frequency of micturition in $16 \%$.

Table 2: Distribution of cases in relation to parity.

\begin{tabular}{|lll|}
\hline Parity & $\begin{array}{l}\text { Total no. } \\
\text { of cases }\end{array}$ & $\begin{array}{l}\text { Incidence } \\
\text { Nulligravida }\end{array}$ \\
\hline Nullipara & 5 & $4.80 \%$ \\
\hline Multipara & 71 & $76.73 \%$ \\
\hline Grandmultipara & 21 & $68.26 \%$ \\
\hline
\end{tabular}

Table 3: Distribution of patients in relation to target symptoms.

\begin{tabular}{|lll|}
\hline Target symptoms & $\begin{array}{l}\text { Total no. of } \\
\text { cases }\end{array}$ & $\%$ \\
\hline Abdominal pain + distension & 28 & 26.92 \\
\hline Abdominal Lump & 17 & 16.34 \\
\hline Bleeding PV & 42 & 40.38 \\
\hline Pelvic pain & 78 & 75 \\
\hline Constipation & 18 & 17.30 \\
\hline $\begin{array}{l}\text { Burning micturition/ } \\
\text { Frequency }\end{array}$ & 16 & 15.38 \\
\hline
\end{tabular}

Table 4: Distribution of abdominal mass according to size of tumour.

\begin{tabular}{|lll|}
\hline Sive & Total No. of cases & $\%$ \\
\hline $6-10 \mathrm{~cm}$ & 55 & 52.88 \\
\hline $11-20 \mathrm{~cm}$ & 44 & 42.30 \\
\hline$>20$ & 4 & 3.84 \\
\hline Ruptured & 1 & 0.96 \\
\hline Total & 104 & 99.98 \\
\hline
\end{tabular}

Acute pain and vomiting were the common complaint in twisted ovarian tumours. Loss of appetite, loss of weight, constipation, difficulty in micturition was common in malignant and large abdominal mass. All patients in present series had undergone surgical treatment, of these, $22.1 \%$ patients had undergone exploratory laparotomy with cystectomy as depicted in table 6 .
Table 5: Diagnostic modality used.

\begin{tabular}{|l|l|}
\hline Diagnostic modality used & Total no. of cases \\
\hline USG & 91 \\
\hline CA 125 & 10 \\
\hline CT & 5 \\
\hline MRI & 4 \\
\hline Ascitic fluid cytology & 5 \\
\hline
\end{tabular}

Table 6: Treatment.

\begin{tabular}{|lll|}
\hline Treatment & $\begin{array}{l}\text { Total no. of } \\
\text { cases }\end{array}$ & $\%$ \\
\hline TAH & 35 & 34.6 \\
\hline Exp. Lap & 24 & 22.11 \\
\hline VH & 3 & 2.88 \\
\hline Exp. Lap fb hyst. & 5 & 54.80 \\
\hline TAH with BSO & 12 & 11.53 \\
\hline TAH with cyst removal with SO & 4 & 3.84 \\
\hline $\begin{array}{l}\text { Debulking surgery with removal } \\
\text { of ovarian tumour with SO }\end{array}$ & 2 & 1.92 \\
\hline $\begin{array}{l}\text { Ovarian cystectomy with } \\
\text { omentectomy }\end{array}$ & 2 & 1.92 \\
\hline LAMA & 1 & 0.96 \\
\hline Myomectomy & 4 & 3.84 \\
\hline Myomectomy with cystectomy & 1 & 0.96 \\
\hline LSCS with Cyst removal & 1 & 0.96 \\
\hline LSCS with fibroid removal & 1 & 0.96 \\
\hline $\begin{array}{l}\text { Lap with hysterotomy with cyst } \\
\text { removal }\end{array}$ & 4 & 3.84 \\
\hline Subtotal Hysterectomy & 1 & 0.96 \\
\hline
\end{tabular}

\section{DISCUSSION}

In the present study the incidence of benign tumor is $83.33 \%$ and that of malignant tumors is $16.66 \%$. Similar finding was seen in study done by $\mathrm{Jha}^{28}$ were $83.9 \%$ of ovarian tumors were benign and $16.1 \%$ of ovarian tumors were malignant. However, in a study done by Ahmed, ${ }^{29}$ the incidence of benign tumors was $59.2 \%$ and malignancy was $40.8 \%$. According to JPMA (2009), there were $72 \%$ benign tumors and $28 \%$ were malignant.

In our study, as in table 1, the range of age was 15-70 years. This correlates well with many studies done in different part of the world. In a study done in Baltimore, ${ }^{31}$ patients with ovarian tumors ranged from 6-98 years. In another study done by Bhattacharya ${ }^{31}$ the youngest patient was 10 years old girl and old age was 73 years old. Our study showed the peak incidence of ovarian tumors in age group more than 40 year and in between 21-25 years which was comparable with study done by Kayasth et al, were peak incidence of ovarian tumors was between 21-40 years. Maximum number of malignancy was seen in older age group. Similar finding was seen in our study were $10.91 \%$ case of malignancy were seen in patients over 40 years. But in the study done by Kayasth, 
$66.7 \%$ cases of malignancy were seen in patients over 40 years. $^{32}$

In our study, the commonest type of ovarian tumor according to WHO classification was surface epithelial tumors $(50.5 \%)$ which was comparable to several studies and among the surface epithelial tumors, serous cyst adenoma was the comments one $(24.44 \%)$ followed by mucinous cyst adenoma $(6.66 \%)$. Second most common tumor seen in our study was germ cell tumor (22.2\%). In our study, mature cystic teratoma (20\%) was the commonest type of germ cell tumor. However, in a study done by Prabhakar. ${ }^{33}$ Mature cystic teratoma was the third commonest tumor.

In our study, $90.5 \%$ of patients were illiterate and only 10 patients were literate. This huge number of illiterate patients signifies their ignorance and thus late medical checkup, diagnosis and treatment. In the study only $8.57 \%$ patients had addiction to some drug and all were tobacco chewer. Tobacco is considered to be associated with an estrogen-deficient state, through disturbed gonadotropin release or enhanced formation of inactive estrogen from estradiol, among other postulated mechanisms. ${ }^{19}$ A negative association with some aspect of smoking or tobacco chewing history was found in most previous studies ${ }^{1,8}$ with the exception of the Nurses' Health Study. $^{22}$

In a case-control study in Italy, ${ }^{23}$ a moderate association was found between the risk of uterine myomas and the consumption of beef, other red meat, and ham, whereas a high intake of green vegetables seemed to have a protective effect.

Regardless of the relative importance of dietary fat and fiber, such studies have established that modulation of the diet can influence estrogen metabolism in premenopausal women, which may in turn influence the risk for fibroids. Likewise, a $17 \%$ reduction in plasma estradiol concentration was accomplished in postmenopausal women who participated in a low-fat diet intervention program. $^{24}$

In the Black Women's Health Study, 25 parous women had on average two births, with a median age at first birth of 22 years and a median time since last birth of 9 years. Time since most recent birth was positively related to the risk of fibroid among parous women. Women who had a birth in the past 5 years had less than half the risk of fibroid compared with women whose last birth was 5 or more years ago.

The decreased risk of fibroid in parous compared with nulliparous women is consistent with results from previous research, ${ }^{1,6,7,13}$ although my study did not confirm the dose-response reduction in risk for parity that has been shown in some ${ }^{1,7,13}$ but not all ${ }^{6}$ studies. Excess body weight appears to weaken the inverse association observed for parity.
A recent NIEHS study demonstrated that a first birth occurring in the mid-reproductive years (ages 25-29 years) was most protective against fibroid. ${ }^{26}$

Majority of the patients had an early age of menarche i.e. 11 years in $29 \%$ and 12 years in $30 \%$. The median age at menarche in the Black Women's Health Study participants was 12 years with range 11-13 years. Epidemiologic studies on age at menarche in relation to uterine fibroid have shown an inverse association. ${ }^{5-9}$ The association between UL risk and early menarche, was also suggested by previous studies. $6,8,9$

Most studies of the relationship of fibroid to menorrhagia and other menstrual cycle characteristics have been based on care-seeking populations, including women undergoing myomectomy or hysterectomy ${ }^{17,18}$ or tubal ligation, ${ }^{16}$ with mixed results.

\section{CONCLUSIONS}

As patients usually come from low socioeconomic status in our hospital, majority of them were illiterate. Patients usually present late when they have symptoms or have any complication. Hence proper screening of the patient is important.

Ultrasound is effective in detecting the abdominal mass, size and type of abdominal mass, so that early diagnosis can be done and treatment can be given as soon as possible.

With proper selection, the size of an ovarian cyst does not necessarily constitute a contraindication for laparoscopic surgery.

Management of these giant intra-abdominal cysts has traditionally required a full midline laparotomy. Minimally invasive surgical technique have been applied to the management of these giant cysts, but only a few cases have been reported, all reported technique include decompression of the cyst to allow for room to work, facilitate manipulation of the cyst and ovary, prevent in advertent perforation and spillage.

When there is sufficient concern for malignancy on the basic of medical history, physical examination, CA125 level and imaging, prompt surgical evaluation is warranted.

There is no definite way to prevent the growth of ovarian cysts, regular pelvic examination are a way to help ensure that changes in the ovaries are diagnosed as earliest possible.

After studying various risk factors it was found that apart from already established risk factors, obesity and uterine fibroid have an important association. Obesity is since now endemic in our country so obesity control can help in curbing down the incidence. 
Recent advances in the development of minimallyinvasive fibroid treatments may improve fibroid management by positively impacting patient care and reducing costs. The knowledge gained in this field will be poised to pursue further researches that are needed to understand and develop prevention strategies, develop new treatment options, and optimize the effectiveness and safety of clinical care.

\section{Funding: No funding sources}

Conflict of interest: None declared

Ethical approval: The study was approved by the Institutional Ethics Committee

\section{REFERENCES}

1. Parazzini F, Negri E, La Vecchia C. Reproductive factors and risk of uterine fibroids. Epidemiol. 1996;7:440-2.

2. Marshall LM, Spiegelman D, Goldman MB. A prospective study of reproductive factors and oral contraceptive use in relation to the risk of uterine leiomyomata. Fertil Steril. 1998;70:432-9.

3. Lumbiganon $\mathrm{P}$, Rugpao $\mathrm{S}$, Phandhu-fung $\mathrm{S}$. Protective effect of depot-medroxyprogesterone acetate on surgically treated uterine leiomyomas: a multicenter case-control study. Br J Obstet Gynecol. 1996;103:909-14.

4. Musey VC, Collins DC, Musey PI. Age-related changes in the female hormonal environment during reproductive life. Am J Obstet Gynecol. 1987; 157:312-7.

5. Dorgan JF, Reichman ME, Judd JT. Relationships of age and reproductive characteristics with plasma estrogen and androgens in premenopausal women. Cancer Epidemiol Biomarkers Prev. 1995;4:381-6.

6. Bernstein L, Pike MC, Ross RK. Estrogen and sex hormone- binding globulin levels in nulliparous and parous women. J Natl Cancer Inst. 1985;74:741-5.

7. Musey VC, Collins DC, Brogan DR. Long term effects of a first pregnancy on the hormonal environment: estrogens and androgens. J Clin Endocrinol Metab. 1987;64:111-8.

8. Musey VC, Collins DC, Musey PI. Long-term effect of a first pregnancy on the secretion of prolactin. N Engl J Med. 1987;316:229-34.

9. Windham GC, Elkin E, Fenster L. Ovarian hormones in premenopausal women: variation by demographic, reproductive and menstrual cycle characteristics. Epidemiol. 2002;13:675-84.

10. Mora S, Diehl T, Stewart EA. Prolactin is an autocrine growth regulator for human myometrial and leiomyoma cells. J Soc Gynecol Invest. $1995 ; 2: 396$.

11. Kawaguchi K, Fujii S, Konishi I. Immuno histochemical analysis of oestrogen receptors, progesterone receptors and $\mathrm{Ki}-67$ in leiomyoma and myometrium during the menstrual cycle and pregnancy. Virchows Arch A Pathol Anat Histopathol. 1991;419:309-15.
12. Walker CL, Cesen-Cummings $\mathrm{K}$, Houle $\mathrm{C}$. Protective effect of pregnancy for development of uterine leiomyoma. Carcinogenesis. 2001;22:204952.

13. Faerstein E, Szklo M, Rosenshein N. Risk factors for uterine leiomyoma: a practice-based case-control study. I. African-American heritage, reproductive history, body size, and smoking. Am J Epidemiol. 2001;153:1-10.

14. Lambe M, Wuu J, Weiderpass E. Childbearing at older age and endometrial cancer risk (Sweden). Cancer Causes Control. 1999;10:43-9.

15. Glass AR. Endocrine aspects of obesity. Med Clin North Am. 1989;73:139-60.

16. Schneider J, Bradlow HL, Strain G, Levin J, Anderson K, Fishman J. Effects of obesity on estradiol metabolism: decreased formation of nonuterotropic metabolites. J Clin Endocrinol Metab. 1983;56:973-8.

17. Spinos N, Terzis G, Crysanthopoulou A, Adonakis G, Markou KB, Vervita V, Koukouras D, Tsapanos V, Decavalas G, Kourounis G, Georgopoulos NA. Increased frequency of thyroid nodules and breast fibroadenomas in women with uterine fibroids. Thyroid. 2007; 17:1257-9.

18. Olive DL, Lindheim SR, Pritts EA. Non-surgical management of leiomyoma: impact on fertility. Curr Opin Obstet Gynecol. 2004;16(3):239-43.

19. Buttram VC Jr, Reiter RC. Uterine leiomyomata: etiology, symptomatology, and management. Fertil Steril. 1981;36(4):433-45.

20. Frank TS, Manley SA, Olopade OI, Cummings S, Garber JE, Bernhardt B et al. Sequence analysis of BRCA1 and BRCA2: correlation of mutations with family history and ovarian cancer risk. J Clin Oncol. 1998;16:2417-25.

21. Fox H, Langley FA. The development of the gonads. Fox H, Langley FA (Eds.). In: Tumors of the Ovary. London: William Heinemann Medical Books Limited; 1976:19-28.

22. Neerja Bhatla. Tumors of the ovary. In: Neerja Bhatla (Ed.) In: Jeffcoate's Principles of Gynaecology. $5^{\text {th }}$ Ed. London: Arnold; 2001:524525.

23. Smith LH, Morris CR, Yasmeen S, Parikh-Patel A Cress RD, Romano PS. Ovarian cancer: can we make the clinical diagnosis earlier? American Cancer Society. 2005. DOI: 10.1002/cncr.21310.

24. Shattuck EP, Mcclure M, Somard J, Labrie F, Narod $\mathrm{S}$, Cough $\mathrm{F}$ et al. Collaborative survey of 80 mutations in the BRCA I breast and ovarian cancer susceptibility gene: Implications for presymptomatic testing and screening. JAMA. 1995;273:535-41.

25. Berek JS. Ovarian Cancer. In: Berek JS (Ed.): Novak's Gynecology, $13^{\text {th }}$ Ed. Lippincott Williams and Wilkins; 2002:1262.

26. Roth LM, Dallenbach-Hellweg G, Czernobilsky B. Ovarian Brenner Tumors. I. Metaplastic proliferating and of low grade potential. Cancer. 1985;56:582-91. 
27. Berek JS, Hacker NF. Staging and second-look operations in ovarian cancer. In: Alberts DS, Surwit EA, eds. Ovarian Cancer: Boston: Martinus Nijhoff, 1985;109-127.

28. Jha R, Karki S. Histological pattern of ovarian tumors and their distribution. Nepal Med Coll J. 2008;1081-5.

29. Ahmed Z, Kayani, HAsan SH, Muzaffar S, Gill MS. Histological pattern of ovarian neoplasm. Pak Med Association. 2000;501:416-9.

30. Zeake JF, currie JL, Rosenshein NB, Woodruff JD Long term follow-up of serous ovarian tumors of low malignant potential. Gyne Col Oncol. 1992; 47:1508.

31. Bhattacharya MM, Shindey SD, Purandare, VN. A clinic-pathological analysis of 270 ovarian tumors. J Postgrade Med. 1980;26:103.
32. Kayastha S. Study of ovarian tumor in Nepal Medical College teaching hospital. Nepal Med Coll J. 2009;11:2002.

33. Prabhakar BR, Maingi K. Ovarian tumors. Prevalence in Punjab. Indian J Pathol Microbiol. 1989;32:276-81.

Cite this article as: Mathur $\mathrm{P}$, Dave A, Gaur P, Mathur P. Clinicopathologic study of large abdominal masses in gynaecological practice and their outcome. Int J Reprod Contracept Obstet Gynecol 2016;5:503-8. 